\title{
Mindful Self-Compassion and Adult Learner Retention in Post- Compulsory Education
}

Suzie Jokic ${ }^{1,+}$, Nicole Jacqueline Albrecht ${ }^{2,{ }^{+},{ }^{*}}$, Sue Erica Smith ${ }^{1, \neq}$

1. Charles Darwin University, PO Box 557 Strathalbyn, Adelaide, Australia; E-Mails: suzie.jokic@gmail.com; Sue.Smith@cdu.edu.au

2. RMIT University, PO Box 428 Hove, Adelaide, Australia; E-Mails: mindwellcoach@gmail.com; nikki.albrecht@rmit.edu.au

‡ Current Affiliation: Charles Darwin University, Ellengowan Dr, Casuarina NT 0810, Australia

$\dagger$ These authors contributed equally to this work.

* Correspondence: Nicole Jacqueline Albrecht; E-Mails: mindwellcoach@gmail.com; nikki.albrecht@rmit.edu.au

Academic Editors: Sok Cheon Pak and Soo Liang Ooi

Special Issue: $\underline{\text { Health Benefits of Meditation }}$

$O B M$ Integrative and Complementary Medicine 2019, volume 4, issue 1

doi:10.21926/obm.icm.1901004
Received: July 15, 2018

Accepted: January 21, 2019

Published: January 23, 2019

\begin{abstract}
Background: Adult learners often engage in formal education because they want to create changes in their lives and are determined to succeed in their chosen field. However, they also come with emotional "baggage" of early educational experiences, frequently have to deal with a multitude of competing demands, have financial strain, may face a lack of support, illness and/or injury. In addition, they are often dealing with the challenges of unfamiliar academic work, competing deadlines and initially lack basic academic skills. As a result, this segment of the population face high levels of stress and low levels of wellbeing. Research suggests that adult learners' wellbeing is of considerable concern and warrants further investigation, as it has greater implications related to attrition/retention and
\end{abstract}

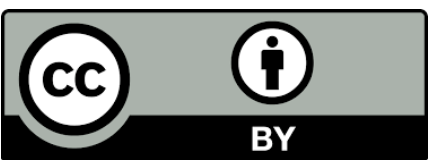

(C) 2019 by the author. This is an open access article distributed under the conditions of the Creative Commons by Attribution License, which permits unrestricted use, distribution, and reproduction in any medium or format, provided the original work is correctly cited. 
academic progression. This small and intimate qualitative study provides rich insights into how mindful self-compassion practices became a powerful tool that supported the adult learners' resolve to continue their education.

Methods: In order to address these research gaps and practical concerns, in the current study the first author identified potential reasons as to why adult learners do not remain in education, explored the rationale for focusing on adult learners' wellbeing, and lastly investigated whether Mindful Self-Compassion (MSC) has the capacity to enhance the wellbeing of adult learners in their first year of post-compulsory education. A form of phenomenological research known as Heuristic Inquiry was applied to understand these problems. First person data was gathered from the first author and four other adult learners who took part in a condensed 6-week MSC program.

Results: This qualitative process produced a rich source of data - indicating that mindfulness and self-compassion helps adult learners enhance their wellbeing. Practising and building self-compassion was found to support adult learners when faced with challenges within their qualifications and in life.

Conclusions: The current research contributes to the collective knowledge on the topic and provides a possible resource building program, which all levels of adult education and more importantly, all modalities (face-to face/on campus and external/online learners), can utilise.

\section{Keywords}

Mindfulness; self-compassion; wellbeing; heuristic inquiry; adult learners

\section{Introduction}

Higher education is described as a major determinant of a population's knowledge, skills, workforce participation, employment, incomes, economic growth, immigration, family formation, and of the educational attainment and future prosperity of subsequent generations [1]. The percentage of Australia's population with a Bachelor degree or higher qualification is high by international standards [1], with $31 \%$ of the population having attained these qualifications [2]. In 2016, nearly 1.5 million students were enrolled in higher education in Australia [3]. In recent years, the number of students engaged in higher learning has increased as a share of the population, with 2011 census data showing $36.6 \%$ of 20 -year-olds attend university or other tertiary institutions - up from $32.6 \%$ in 2006 [1].

Newly formulated and alternative pathway programs that enable mature age students in noncompulsory education to attend has been a key driver in the expansion of the Higher Education sector (see https://www.studyinaustralia.gov.au/english/australian-education/educationpathways). In the past, a student was required to complete secondary school with high grades to attend university or apply as an adult entry student and sit an examination. Presently, if a student has low or no Australian Tertiary Admissions Rank (ATAR) they can still apply to go to a university after they successfully complete an enabling program. This broadening access to Australian universities and other levels of adult education institutions is laudable as an achievement because it provides a more equitable access to both domestic and international students, but with it 
creates responsibilities from all levels of government and education institutions to foster the wellbeing of students.

An unfortunate ramification of more equitable and flexible pathways to higher learning is rising levels of distress in the system. Adult learners (those coming directly from school aged 18-23 years and "non-traditional students" aged above 24 years) often engage in formal education because they want to create changes in their lives and are determined to succeed in their chosen field. However, they also come with "emotional baggage" of early educational experiences, frequently have to deal with a multitude of competing demands, have financial strain, may face a lack of support, illness and/or injury. In addition, they are often dealing with the challenges of unfamiliar academic work, competing deadlines and initially lack basic academic skills. These stressors are often exacerbated when they start their studies, with this segment of the population facing high levels of stress and low levels of wellbeing. A study undertaken by Stallman, identified $16 \%$ of university students with low levels of distress, $65 \%$ with moderate to high distress and $19 \%$ with high distress [4]. In comparison, within the general population, $21 \%$ experienced moderate to high distress, and 3\% reporting high levels of distress. The stress and anxiety experienced by first year adult students has considerable effects on students' concentration, short-term memory, motivation, energy levels and other academic performance, such as, attendance, underperformance, or delays or failure to submit assessments [5].

Preliminary evidence suggests that psychological wellbeing in adult learners is of considerable concern and warrants further study, as it has greater implications for attrition/retention and academic progression [5-13]. In the present study, we explore in-depth a method to help adult learners successfully navigate the pathway of higher learning with a focus on three main areas. The first being to identify potential reasons why adult learners struggle to remain in education; the second to understand whether learning and practising principles of Mindful Self-Compassion (MSC), created by Germer and Neff [14], can be used as a tool for ameliorating suffering and enhancing the wellbeing of adult learners in their first year of study; and the third to determine whether MSC provides a possible tool in building resilience and offers a potential strategy for improving the retention of adult learners. We hypothesise that MSC techniques will support adult student wellbeing, which may in turn assist students to remain in their courses. MSC was chosen because research indicated that whilst other mindfulness-based programs provided present moment awareness, MSC specifically focuses on helping individuals learn strategies to cope with suffering. The program focusses on an active component of self-soothing behaviour when encountering moments of stress [15].

A qualitative methodology was applied in order to explore these three main problems. To date, there has been a small amount of quantitative research on how the MSC program is beneficial in the field of education [16]. However, it fails to capture the totality of the human experience and provide a holistic account of the student's experience as they journey through MSC. Due to MSC's focus on the individual and their wellbeing, Reyes considers it important to gain a narrative perspective of the ways in which individuals experience the program [17] - seeking insights into their subjective experiences, deeper attitudes, feelings and behaviours.

In this article, we report on part of the findings from the study. This is the first known study of its kind to examine how an MSC course affects adult learners in Australia or Australians, in general. Before discussing the results, the nature of mindfulness and MSC is presented, a literature review 
of MSC in education is provided, and the methodology and methods guiding the research project are described.

The study was approved in 2017 by the ethics committee at the International Graduate Centre of Education at Charles Darwin University, Northern Territory, Australia. The Committee was satisfied that the research proposed conformed with: the general principles set out in the current National Health and Medical Research Council regulations; the policy of the International Graduate Centre of Education: H16113-Master of Education (International) Coursework Ethics Application-non-vulnerable human ethics.

\section{Mindfulness and Mindful Self-Compassion (MSC)}

\subsection{Mindfulness}

For centuries, the concept of mindfulness has attracted an array of rich interpretations and definitions but may simply be described as a natural human capacity, which involves observing, participating and accepting each of life's moments from a state of equilibrium or loving kindness [18]. It can be practiced through meditation and contemplation but may also be cultivated through paying attention to one's every day activities, such as, eating, gardening, walking, listening and school-based activities such as university work [18]. Mindfulness is commonly used in the academic literature in three main ways [18]. First, it is used to refer to a state, trait or way of being, which has prescribed characteristics, such as; acceptance, non-striving and non-attachment (see Table 1 for more characteristics) [19]. Next it is applied to programs that cultivate a mindful state, for example, the Mindfulness-based Stress Reduction program. And lastly it denotes a type of meditation technique - mindfulness meditation [18].

Mindfulness has been called a "revolution" [20], with the practice now widely cultivated in many countries around the world. This popularity has, however, come at a cost with researchers finding that mindfulness is being misused in schools [20] and workplaces [21]. For example, Purser and Milillo argue that:

... corporations have jumped on the mindfulness bandwagon because it conveniently shifts the burden on to the individual employee: stress is framed as a personal problem, and mindfulnessbased interventions are offered as means of helping employees cope and work more effectively and calmly within such toxic environments. Cloaked in an aura of care and humanity, this corporate takeover refashions mindfulness as a safety valve, a way to let off steam and as a way of coping and adapting to the stresses and strains of corporate life. ...Mindfulness training has wide appeal because it can be utilized as a method for subduing employee unrest, promoting a tacit acceptance of the corporate status quo, and as an instrumental tool for keeping attention focused on corporate goals.

At the university-level mindfulness courses and therapy are also being commonly used by counsellors and teachers as a means to help students manage the stresses of university life [18]. However, the second author has personally found that while cultivating mindfulness does help some students manage university-life, it cannot compete with the demands of 100-hour per week courses. 
Table 1 Mindful Characteristics.

\begin{tabular}{|c|c|}
\hline Characteristic & Description \\
\hline Acceptance & Seeing and acknowledging things as they are in the present moment. \\
\hline Authenticity & $\begin{array}{l}\text { Openness, honesty with the self and others and gaining a realisation } \\
\text { of the beauty and completeness of each human being. }\end{array}$ \\
\hline Awareness & $\begin{array}{l}\text { Awareness of thoughts, feelings and habits. Seeing the "big picture" } \\
\text { rather than giving into one's conditioned and habitual behaviour. } \\
\text { Awareness of the wider environment. }\end{array}$ \\
\hline Curiosity & A spirit of interest, investigation and exploration. \\
\hline Discernment & $\begin{array}{l}\text { The operation of wisdom where you can see the subtleties - the } \\
\text { thousand shades of grey between black and white. }\end{array}$ \\
\hline $\begin{array}{l}\text { Empathy and } \\
\text { compassion }\end{array}$ & $\begin{array}{l}\text { A respectful consideration of one's own experience and of another } \\
\text { person's experience - including compassionate listening and } \\
\text { communication of feelings, needs and desires. This consideration will } \\
\text { naturally extend to include the environment, with an aim of reducing } \\
\text { oppression, injustice and suffering. }\end{array}$ \\
\hline Equanimity & $\begin{array}{l}\text { A quality of wisdom, an evenness and steadiness of mind that } \\
\text { comprehends the nature of change. }\end{array}$ \\
\hline Gentleness & $\begin{array}{l}\text { A soft, considerate and tender quality; however, not passive, } \\
\text { undisciplined or indulgent. }\end{array}$ \\
\hline Letting go & $\begin{array}{l}\text { Non-attachment, not holding on to thoughts, feelings or experiences - } \\
\text { letting things be as they are. }\end{array}$ \\
\hline Loving kindness & $\begin{array}{l}\text { A quality where you truly wish another well - to be healthy safe, free } \\
\text { from harm and free from fear. A quality embodying friendliness, } \\
\text { benevolence and love. Loving-kindness extends to all that surrounds a } \\
\text { person - including the self. }\end{array}$ \\
\hline Non-attachment & $\begin{array}{l}\text { Letting go, not grasping and clinging to outcomes. Allowing events to } \\
\text { simply unfold. }\end{array}$ \\
\hline Non-judging & $\begin{array}{l}\text { Impartial witnessing, observing the present moment without } \\
\text { evaluation or categorisation. }\end{array}$ \\
\hline Non-reactivity & $\begin{array}{l}\text { Ability to respond with consciousness and clarity, instead of } \\
\text { automatically reacting in a habitual or conditioned way. }\end{array}$ \\
\hline Non-striving & $\begin{array}{l}\text { Non-goal-orientated, remaining unattached to outcome or } \\
\text { achievement. }\end{array}$ \\
\hline $\begin{array}{l}\text { Openness } \\
\text { (Beginner's mind) }\end{array}$ & Seeing things newly, as if for the first time. \\
\hline Patience & Allowing things to unfold in their own time. \\
\hline Trust & $\begin{array}{l}\text { Developing a basic trust in your experience and your own inner } \\
\text { wisdom. }\end{array}$ \\
\hline
\end{tabular}




\subsection{Mindful Self-Compassion}

"Mindfulness is the foundation for self-compassion" [22], with compassion for the self, other and environment also considered to be a critical component in the majority of mindfulness programs [23]. The prominence and receptivity of mindfulness in the Western world has helped fuel the contemporary interest in the construct of self-compassion [24] (become an entity on its own. Research on self-compassion and its effectiveness on a wide spectrum of life's difficulties, has escalated since the early 2000s and is emerging as a new area of research in the social sciences. This recent interest has resulted from psychologists looking for alternative and additional practices that provide a buffer for individuals suffering from psychological distress. The additional element of the focus on self-compassion over just mindfulness is that there is an intentional effort to be compassionate towards any mindfulness of suffering; it is the deliberate act of selfcompassion that encourages the self-soothing elements of healing.

The term compassion consists of 4 Sanskrit words Karuna (suspension of temporary happiness to attain ultimate happiness), Prajna (insight in the true nature of reality), Maitri (good will towards others) and Upaya (cultivation of a compassionate state of mind) [17]. From a Buddhist perspective, self-compassion is a "response to personal suffering with wisdom, loving-kindness, and mindfulness that extends beyond the self to all others who are suffering" [17]. The Western perspective, the English version of compassion, comes from Latin roots com (with or together with) and pati (suffer or to suffer with) [25]. Self- compassion describes the act and intention of simply giving the same kindness and compassion one would give to others to themselves [26-28]. When there is genuine self-compassion, there is a recognition that someone is in pain, viewed with a sense of acceptance to it and finally a desire to alleviate or lessen the pain. Self-compassion involves being kind to oneself in instances of failure, perceiving one's experiences as part of the larger human experience, and holding challenging feelings with mindful and compassionate awareness [29]. In essence it is to be open and receptive to one's suffering and secondly, responding to suffering [30]. Or simply summarised, it is being sensitive to the experience of suffering of self and others, coupled with a deep commitment to try and prevent and relieve that suffering [31].

The interest and attention self-compassion has received since 2003, derives predominately from two research articles that defined and measured self-compassion - the Self-Compassion Scale (SCS) by Neff [32, 33] (see http://self-compassion.org/the-program/). Neff described selfcompassion as compassion directed inward, relating to the self as the object of care and concern when faced with the experience of suffering [33]. Neff has conceptualised self-compassion as consisting of three main elements: kindness, common humanity and mindfulness [32].

1) Self-kindness - extending kindness and understanding to oneself rather than harsh judgment and self-criticism

2) Common humanity - seeing one's experiences as part of the larger human experience rather than seeing them as separating and isolating, and

3) Mindfulness - holding one's painful thoughts and feelings in balanced awareness rather than over-identifying with them [32].

These three concepts are distinct conceptually but they can also overlap and engender one another [32]. In addition to these three components of self-compassion, Reyes [17] added wisdom as the fourth component. Wisdom acknowledges the internal experience; the suffering, 
ruminations and illusions just as they are and more importantly, provides individuals with the skills to transform their suffering.

\subsection{Mindful Self-Compassion - A Literature Review}

As the MSC program was only developed in 2010 [22], there has naturally been limited research surrounding the course and its potential in the adult education sector. Within the Australian context research is non-existent. The preliminary research on the topic (post Neff's initial papers $[32,33]$, first focussed on the theoretical reasons as to why the characteristic of self-compassion supports students. Researchers have used the self-compassion scale to measure how kind and understanding individuals are toward themselves in instances of pain or failure. The current evidence-base from the time-period of 2003-2013, has revealed that self-compassion is positively correlated with student wellbeing [24, 34-39]. Further, Neely and colleagues concluded that selfcompassionate college students not only have less fear of failure, but are also more likely to try again after failing. In addition, the researchers found that the way students manage their challenging emotions, when faced with disappointments, is a significant contributor to personal wellbeing. Rather than responding with harshness and criticism, self-compassionate individuals tend to be more kind and understanding to themselves when faced with challenges. Neff and colleagues also affirm that MSC supports academic motivational patterns [34]. That is, students rather than seeing failure as a negative, perceive failure as a learning opportunity; motivating them to focus on and accomplish required tasks [34].

It is hypothesized that the practice of self-compassion gives students an opportunity to develop a healthy self-concept [31]. It does this by neutralising the negative emotional patterns students hold onto and generates enhanced feelings of kindness and gratitude. It also reminds students that they no longer need to be self-consumed and over-identify [32] with their suffering and allows them to understand that other students experience similar thoughts, feelings and behaviors. Self-compassion helps to facilitate the learning process by freeing individuals from the debilitating consequences of harsh self-criticism, isolation, and over identification in the face of failure, and instead provides students with a disposition of self-kindness, a sense of common humanity, and emotional balance [34]. This constructive attitude towards the self appears to help students focus on mastering tasks at hand rather than worrying about performance evaluations; assisting them to develop confidence in their competence as learners, and fostering intrinsic motivation.

Building on this body of research, Neff and Germer found in a pilot randomized controlled trial (RCT) that self-compassion is a teachable skill that enhances overall quality of life, and this heightened sense of wellbeing is sustainable for at least 6 months post involvement in the course [27]. They also reported that the MSC program has the capacity to enhance self-compassion, mindfulness, life satisfaction, and happiness; as well as decrease depression, anxiety and stress [27]. In another outcomes-based study, where the MSC program was compressed to a 3-week duration, from the recommended 8-weeks, students were shown to have an increase in life satisfaction, optimism, self-confidence, resilience and wellbeing; combined with a reduction in self-criticism and negative rumination [16]. These results indicate that even a condensed program can help buffer students from the challenges faced in adult education.

In addition, some recent studies indicate that teaching self-compassion is not only beneficial to students but has the capacity to assist professionals in the wider community. Olson, Kemper [40], 
conducted a study with first year paediatric and medicine residents and concluded that selfcompassion was positively associated with resilience and inversely associated with burn outs. They found that self-compassion may ameliorate emotional exhaustion, especially in relation to interns facing their first experiences in their new role. Thus, teaching skills to cultivate self-compassion can act as a prophylactic. This is further supported by Şenyuva, Kaya [41], who found that selfcompassion was positively associated with emotional intelligence.

\section{Materials and Methods}

\subsection{Methodology}

A qualitative approach known as Heuristic Inquiry $(\mathrm{HI})$ was used to identify potential reasons as to why adult learners do not remain in education, explore why it is important to focus on adult learners' wellbeing, and lastly investigate whether Mindful Self-Compassion (MSC) has the capacity to enhance the wellbeing of adult learners in their first year of study. HI was selected for the inquiry because it is consistent with the underlying principles and characteristics of mindfulness. It involves focusing on the present moment with non-judgmental attention on the body, mind and spirit. It provides researchers with a process for reflection on a personal experience to gain understanding of the underlying structure, order and coherence of a problem, which is analogous to phenomenology. Denford-Wood, who used the methodology to explore the mindfulness of Seminaria, explains that $\mathrm{HI}$ validates as research evidence the symbolic growth experience (SGE) [42, 43], frisson [44] and peak experience [45], consistent with being "in the flow" or "the zone" [46] and is recognized as an ideal methodology for exploring individuals' journeys through transformative growth practices [47], such as MSC. HI honors human experience [48]. The methodology originates from Clark Moustakas's book, Loneliness, published in 1961, where the author provided an autobiographical account of his loneliness when having to make a decision about his daughter's health [49]. The word heuristics comes from the derivation of the ancient Greek word "heuriskein", which means "to discover" or "to find" [50]. Researchers when using heuristics aim to discover meaning through self-reflection, exploration and elucidation.

$\mathrm{HI}$, like many other qualitative approaches to research, is interested in how humans perceive and describe experiences of personal significance. Through a compassionate approach, the methodology encourages the researcher to move towards an open discussion with co-researchers; facilitating what is described as "an emotionally connected scientific inquiry" [51, 52]. The researcher's perceptions, feelings and meaning making play a central and critical role in the data collection process [52]. During the synthesis of data, the researcher's own thoughts, feelings and expression of his or her perceptions on a research problem are harmoniously interwoven with the co-researchers' (participants') lived experience [52]. This is said to result in a comprehensive description of a reflective structural analysis of the essences of the experience [53].

The first author (Suzie) chose the methodology due to the perception that truth and reality in any phenomenon starts with the researcher's perception [53]. Suzie first needed to reflect on the meaning of her own personal experience of the research problem in order to gain intersubjective validity with her participants. In addition, $\mathrm{HI}$ is well suited for this study as it is conducive to mindfulness and self-compassion. The methodology invites the researcher to focus on the present moment with non-judgmental attention on the body, mind and spirit. 
The main difference between a traditional phenomenological paradigm and qualitatively orientated heuristic methodology is that unlike phenomenology, the "heuristic scientist seeks to discover the nature and meaning of phenomenon itself and to illuminate it from direct first-person accounts of individuals who have directly encountered the phenomenon in experience" [50]. The focus in a heuristic research is that from the beginning to the end of the research investigation, the researcher herself, is using introspective investigation. Moustakas elaborates: "Heuristic research involves self-search, self-dialogue, and self-discovery; the research question and the methodology flow out of inner awareness, meaning and inspiration."

Suzie used Moustakas [50] seven phases of research to explore and explicate the research problem. Djuraskovic and Arthur [52] write that according to Moustakas [50], heuristic research begins with the question that needs to be illuminated or answered. It represents a scientific search that involves seven concepts: identifying with the focus of inquiry, self-dialogue, tacit knowing, intuition, indwelling, focusing, and the internal frame of reference. The researcher is present in all of the aspects of this study; she is the participant, the story teller, the facilitator and the researcher. Given the role of the researcher, a small number of participants is recommended when applying the methodology and methodologies in general that require in-depth analysis [54]. For more details on Moustakas' seven concepts and the explication of this in-depth level of inquiry please see Moustakas [50] and/or Djuraskovic \& Arthur [52].

\subsection{Methods}

The research project involved two main phases of data collection conducted over a 2-year period. The first phase, involved Suzie delving deeply into her experience of the research problem; striving to understand insights into the challenges and barriers she faced while completing postgraduate studies over a 2-year period. She feels practicing mindfulness and self-compassion was an important method to improve her own wellbeing and resilience. Suzie's perceptions were predominately expressed through art work (see Figure 1 for an example) and personal journaling. The second phase involved exploring how four other participants (co-researchers) made sense of their studies and understanding how a 6-week Mindfulness and Self-Compassion course affected their wellness and learning journey. In the following sections, we provide: a description of the Mindful Self-Compassion (MSC) program; outline participant and recruitment details; how the data was collected and briefly overview methods used to assess qualitative rigor.

\subsubsection{Program Description}

In this research project, participants took part in the Mindful Self-Compassion (MSC) program. MSC, like the Mindfulness-based Stress Reduction program is usually run over an 8-week period online or face-to-face. However, due to participants' time constraints and potentially competing assessment deadlines, Suzie delivered a condensed version of the program. Sessions were facilitated by Suzie, who was involved with the inaugural MSC teacher training held in Australia in 2017 (see the following section for more details on the teacher's qualifications). Classes were delivered over a 6-week period with a one-day workshop. Each week, research participants took part in a 2 to 2.5-hour session, which included homework and encouragement to continue with personal practice at home. The compressed program also included a one day session held on the weekend. The delivery of the program explicitly taught the skills of self-compassion; it also 
contained a wide variety of meditations and informal practices that are used to strengthen the habit of responding mindfully and compassionately to emotional challenges. Each participant was given the Mindfulness Self-Compassion workbook by Neff and Germer [55] - a 50-page book, which contains definition, information on the science of compassion, tips on how to respond when resisting self-compassion, informal practices such as the self-compassion break and formal practices that included the Soles of the Feet Meditation (see https://www.youtube.com/watch?v=cj3nS5y8TD4).

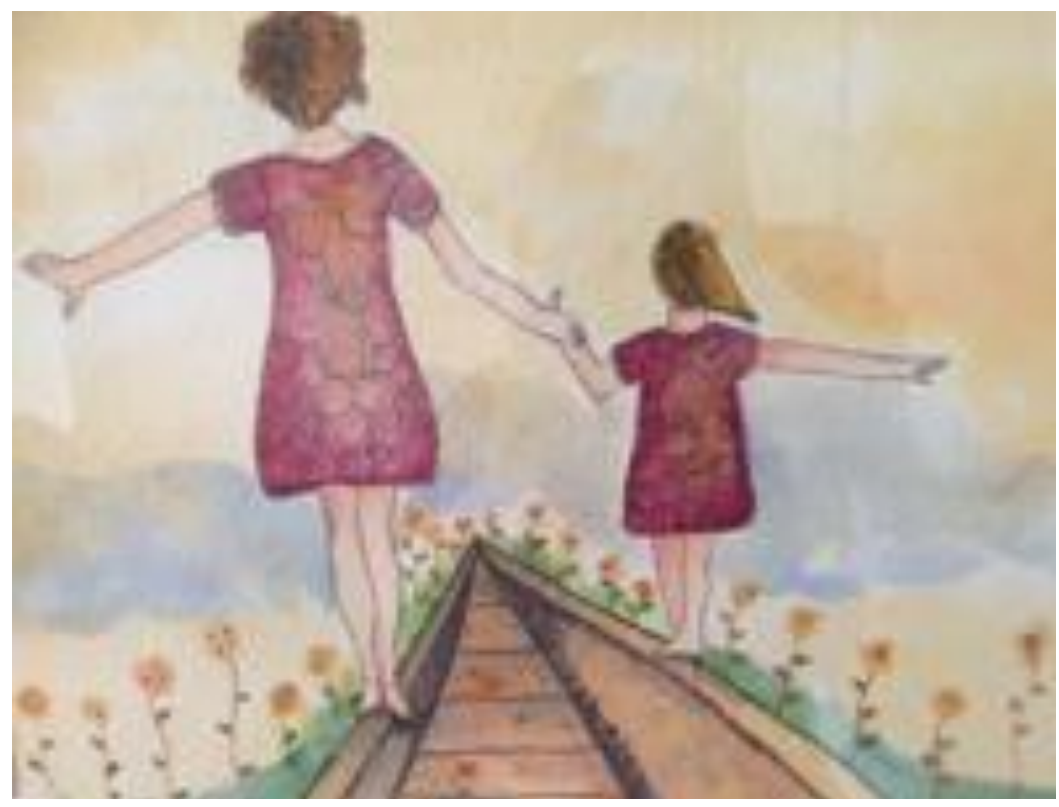

Figure 1 Walking with Fear by the first author.

\subsubsection{Teacher Qualifications}

Suzie has been an active meditator for over 20 years but struggled with the stringent teachings of meditation (i.e. daily formal practice, sitting in a certain way, eyes slightly open and hands in mudra position). In 2011, she undertook the Mindful Awareness Parenting (MAP) Practitioner training course, where her interest and understanding of mindfulness and first introduction of the concept of "self-compassion" blossomed. The non-judgemental focus of the practice, for example, informal practices of mindfulness, such as "being in the now" during daily routines, combined with the practical components and exercises in self-compassion i.e. self-compassionate letter, resonated with her. She began teaching MAP to parents on a regular basis. In 2015, she participated in a Mindful Self-Compassion intensive course and it was during this period of time that her practice expanded to also include self-compassion. She started a mindfulness group called "Inner Health Club" at her local community centre, which was a weekly group that explored mindfulness and self-compassion. She also teaches "Mindfulness for beginners" regularly at Workers' Education Association (WEA) of South Australia, Australia's largest non-government adult community education organisation. In 2017, she was involved in the inaugural 6-day residential MSC Teacher Training in New South Wales, facilitated by Dr Christopher Germer, Dr Steven Hickman and Tina Gibson. The training is built around the eight-weekly sessions of MSC, which includes short talks, group exercises, discussion and practice. 


\subsubsection{Participants}

Four participants living in South Australia took part in the abridged version of the MSC program. Participants were recruited through word of mouth and Facebook posts on personal and community sites. Prior to the program, the first author held an information session to inform participants of the study and detail the paper work related to ethics and questionnaires. Two of the participants attended Technical and Further Education (TAFE) and two attended university. They had a median age of 40 . Three of the students were mature aged learners and one was a school leaver. The students were undertaking the following university courses: Early Childhood Education and Care; Mental Health Peer Support; and Midwifery and Social Work - qualifications that ranged from Certificate III through to Bachelor level. All were active students with the exception of the Social Work student who deferred in the semester prior to the commencement of MSC program. The participants were all female and race/ethnicity diversity and socioeconomic status were not questioned during the research. They had little knowledge about self-compassion, however, one participant had completed a mindfulness course.

\subsubsection{Data Collection Method}

A range of data was collected from the participants via questionnaires, email correspondence, casual dialogue and interviews over a 5-month period. Questionnaires were provided at the information session prior to commencing the MSC course. The questions were aimed at understanding: the participants' prior knowledge of mindfulness and self-compassion; why they enrolled in their course of study; whether they were currently receiving support through student services; their awareness of educational institution support services; their general experience of being an adult learner; whether they had already experienced any feelings that affected their wellbeing and resilience; and how the participants responded when their wellbeing was affected.

Individual semi-structured interviews were conducted by the first author over two weeks after the completion of the MSC course, to help facilitate an open exploration of participants' experiences during and after the course. Three participants completed the interview after the course face-to-face and one via the telephone. Participants were given questions (see Figure 2) prior to the interview in order to increase their reflection and contemplation of the results of their participation. The aim of the interviews was to explore the qualitative experiences of the participants themselves, while at the same time looking for descriptions of helpful and not so helpful aspects of the MSC program. Emails were collated as research data and interviews were recorded and transcribed by the researcher. Interviews were guided by inner experiential time, rather than the "clock" and the participants were encouraged to allow the flow of ideas, thoughts, feelings and images to unfold and be expressed in whatever way that they felt inclined to share their data [50].

The first author undertook a thematic analysis of the data, and three months after the MSC course completion, a follow-up email was sent to all the participants so that they could membercheck, edit and approve the final version. They were also encouraged to respond to the email with any follow up experiences, reflections, realisations and/or examples. Three out of the four participants included additional information about the results of their involvement in the study and their continued improvements, practices and realisations. 


\section{Interview Schedule \\ General}

Q1. What has been useful for you in the MSC course?

Q2. What challenges have you experienced during the participation of this program?

Q3. How has the MSC program assisted your wellbeing as a student, and in your life more generally?

\section{Self-compassion and Mindfulness Exercises}

Q1. How have you experienced doing the exercises you have been introduced to?

Q2. How has it been for you to do the exercises at home? (hindrances and solutions)

Q3. Which exercises were the most helpful?

Q4. Which exercises where the least helpful?

Q5. Are you going to continue to do some of these exercises? If so, which ones?

Q6. When it is difficult to pay attention or to do exercises are there other things that help you?

Q7. Are you going to continue to do some of these exercises? If so, which ones?

\section{Changes after the MSC Program}

Q1. Are you doing something different today? Describe an episode where you did something different than before.

Q2. Do you experience any changes in how you now cope or deal with challenging situations?

Q3. How, if at all, has learning Mindful Self-compassion affected your relationships with other people?

Q4. How has doing the MSC program, if at all, supported your ongoing studies?

\section{Core MSC Concepts}

Q1. What is your understanding of self-compassion? In what ways do you currently practice self-compassion?

Q2. What is your understating of mindfulness? In what way do you currently practice mindfulness?

Q3. What has been the most beneficial aspects of the MSC course for you?

MSC and Higher Education

Q1. What benefits, if any, would you see for MSC being used more broadly in Higher Education?

Figure 2 Interview schedule.

\subsubsection{Methods for Ensuring Qualitative Rigour}

We applied a number of methods to ensure qualitative rigour. First, commensurability between the methods, methodology and epistemology was assured. We then took into account broad criteria established for qualitative research $[56,57]$. Lastly, method-appropriate criteria, a method that adjusts for the nuances and differences between qualitative approaches [58] was applied.

\section{Results}

Due to the extensive nature of the results, in this article we primarily present Phase Two of the research, which involved exploring the evolution of the four participants' (co-researchers) attitudes and feelings towards post-compulsory education and learning Mindful Self-Compassion (MSC). Following, we present the participants' thoughts and feelings prior to, during and after the MSC program. 


\subsection{Prior to the Participation of the MSC Program}

The results indicated that prior to practicing mindfulness and self-compassion, the participants and the researcher experienced self-doubt, insecurity and fear of failure, an inability to remain focused, and to start and/or complete study-related tasks. Some common themes that were revealed were: negative rumination; a lack of focus; resistance to completing assessment tasks; which in turn led to a negative spiral of personal wellbeing. All of the participants had thoughts of quitting, withdrawing or postponing studies. One of the students had recently deferred, another participant had started multiple qualifications in the past and never completed any, another failed to continue with tertiary education because of feeling like a failure when undertaking studies in her younger years; and the first researcher deferred starting her Masters and one topic due to self-doubt.

\subsection{During the Course}

There were discussions and reflections and some email contact during the program. During the program the first author and co-researchers related that they: enjoyed the course; were beginning to learn how to enact self-compassion; and self-care in their lives and were developing enhanced levels of meta-cognition and reflection. Following are some notable reflections from the participants.

After the first session, one of the participants, via text, shared how much she enjoyed the program:

Hi Suzie. I have been meaning to text you all day. Thank you so much for last night. I thoroughly enjoyed it and it was just what I needed as well. Got home and could have got into a yelling match with my son. Instead walked away and did some self-care for myself. So, thanks. The other girls are just lovely. Also, you have a very warming presence about you.

Halfway through the course some of the participants chose to reflect via email on their experience:

I am enjoying the course, and surprisingly have not found it very hard to focus on MSC and my own thoughts and am learning things about myself. Although I do find it hard to remember to do it every day but when I do, I really enjoy it.

I have tried to be open minded and positive... really enjoy being mindful as often I wouldn't be mindful of my own thoughts and feelings and always put them aside.

Trying to remember to be non-judgmental towards people at work that are hard to work with...striving to keep away from the gossip and the complaining that they are doing.

Doing self-care and reminding myself that I don' $t$ need to take this on.

I am practising self-compassion every day. Using my self-love words, phrases. They are helping me to step back and look at the here and now.

I feel that I am a lot calmer with my emotions and how I react to situations.

I am talking to myself more self-compassionately.

When my thoughts wander to painful thoughts/past I bring myself back to the here and now.

These reflections indicate that the participants were engaging positively, working to become less-judgemental, becoming calmer and more self-compassionate and taking care to make the 
exercises a daily habit. In the next section, we highlight how each person felt after completing the MSC course.

\subsection{After Completing the MSC Course}

\section{Sarah}

Mother of three children (2 adults and one child)

Working as well as studying

Sarah has previously been enrolled in many courses but never completed any. Some include: Business Administration, Advertising and Graphic Design, Art, and Business Management. She said that there were many reasons for this including demands of children and an inability to navigate online systems related to external studies. After further reflection, during the interview, she did acknowledge feeling overwhelmed and a strong feeling of inadequacy. She is currently completing her Certificate III in Early Childhood and Care and once finished, she will go on to study a Diploma in Counselling, which she had already paid for but postponed due to the TAFE certificate. She said she thoughts many times of quitting; felt sad, a lack of self-worth, scared, anxious and had a fear of failure. She said that she felt like her thoughts go in a "downward cycle" - where she becomes teary, upset, quiet, and hides from people. Sarah chose to do the course because she, "wanted to be more self-compassionate, form better patterns of habits of being positive about herself."

Some of her reflections after the course included:

I have learnt the valuable skills to be mindful and self-compassionate. For example, thinking of anchors to be more mindful. Having loving kindness phrases to use has been useful. Each session I learnt new thoughts that I can use, like "thoughts are not real" and "what would my friends say to me in this time of need".

I feel I am a little stronger to keep my thoughts more positive rather than heading into a downward spiral.

I feel a bit more relaxed about it (her studies) and am being kinder to myself.

A notable reflection was that she now realises how much care and love she gives to others with very little given to herself. She has become more mindful of what she is doing and feeling. She is grateful that she has gained skills to become more mindful and self-compassionate on a daily basis. She found most valuable two exercises: self-compassionate break and affectionate breathing exercises. She also likes to concentrate on the sounds around her and having a sensory item, like a crystal, to remind her to practice. She is noticing that she is using loving kindness phrases more often. She has also started a gratitude diary, in order to help her develop a more positive attitude. Having the workbook, tools and exercises to use will help her continue her practice and develop mindfulness and self-compassion traits until they become "a way of life".

Sarah, during the interview, gave an example of where she changed her response patterns:

After someone said something quite negative to me, I initially was upset, but with the thoughts I learnt from MSC course I was able to look at it differently and pick up my feelings about myself quicker. I looked how it was the other person's issue and how I didn't do anything wrong and thought about my loving kindness phrases: 'learn to be kind to myself' 'accept myself, exactly as I am. 
When asked whether MSC could be used in adult education, she stated that it would be beneficial for those students who have a "fear of failure" and "it would give people more confidence in themselves and their studies".

One of the outcomes from participating in the program is that it has helped her notice when she is procrastinating and intentionally use mindfulness and self-compassion tools when feelings of fear and inadequacy arise. She stated:

I think what it has done for me is to allow me to mindfully notice that I get flustered easily.

I go to sit down to do the work...I can't sit still... I get up to make a cup of tea...or clean...It is a little procrastination but I think it is more of overwhelm...then I remember to breath...

I will also use the meditations to get me through, when it comes up next time.

\section{Kate}

A mother of three adult children. One living at home who is on the autism spectrum.

Working two jobs and studying.

Kate has already completed two qualifications and is currently undertaking another TAFE certificate, Certificate IV Mental Health Peer Support. Prior to undertaking the course, she experienced feelings of not being good enough, self-doubt, apprehension, anger, questioning her ability and balancing work/study/life commitments. She noticed that when her wellbeing was affected she became increasingly anxious and stressed. Kate would also said that she would have no patience for colleagues and be short tempered at home with her family.

She stated that the MSC course was useful for her because it gave her:

- a different attitude, she made the following statements "I'll get it done" "I am easier on myself" "It's Ok" "I'm less likely to jump on board onto other people's rubbish" "let it go easier"

- an increased awareness

- a shift in perspective "see the reality of the situation"

- an ability to feel a lot calmer "not so reactive"

- great benefits for work and home as it helped her stop overacting to her frustrations

- the ability to break things down into steps and not feel overwhelmed

- a reminder to "stop myself and listen"

- increased empathy, she stated the course gave her "Greater empathy for others and myself"

- an ability to notice when "to move away and become more aware"

- the self-compassion to "sit with my pain and experience it"

- a reminder to be in the here and now

An important benefit of being involved in the course, was noticing how it affected her relationships with other people and herself. She said that she had become more patient with her adult son living at home and noticed that he is also starting to become more mindful and selfcompassionate without being explicitly taught the practices. Kate also communicated:

With my colleagues, especially junior staff, I used to be very judgmental and involve myself in office gossip and not form my own opinions on them. I realise I am less judgmental and will stop and try to get to know them. With one particular junior staff member, who other members gossiped about, I took the time to get to know and realised we shared commonalities. 
I have noticed that I am less judgmental on junior staff abilities. More patient with them. It gets tiring training them up. Now I am realising that they have learned things differently, it still works...they are doing the best they can...they are doing what they think is right...I stop and focus on what is the reality of the situation...l am trying not to personalise everything. More patient and willing to show them.

A profound realisation Kate had was that she noticed a tendency to project her self-doubts onto others, especially junior colleagues, but since the course, realised that she is the one who is not confident. She relayed:

I often am the one to encourage other people, and give them little positive messages like...be kind to yourself...you are doing a great job...give yourself a break...and write them on the white board at work. Now I am remembering those words and saying them to myself... I am doing the best I can...It will be OK!

An example of how her response and behaviour patterns changed is as follows:

Today at work, there was a linen trolley full and instead of emptying it, the staff continued to fill it up. Normally, I would react ... "EMPTY the bloody thing"'. Today I took the trolley down myself. I remembered to STOP and I took a deep breath. Put my hands on my heart. I offered myself a soothing touch.

When asked about how the MSC program might supporting her ongoing studies, she replied:

I feel more confident... remind myself that I am doing a great job. Everyone is also feeling the same feelings as me. I have learned that resubmitting my assignment isn't that I've failed, I just need to add some more to the questions. If I don't do any study for a few days, I don't beat myself up. Instead, I am kinder to myself. I will get it done and I needed that time for myself.

In her concluding comments about the MSC being used in Higher Education, she stated:

If everyone was able to do this course before they embarked on any education, I believe it would make a big difference to the way they approach their study and life in general. We grew up in a time where talking about yourself and looking after yourself just didn't happen. We need to be healthy in our minds - to be able to show real compassion to others and ourselves. I always felt like a failure when doing my nursing studies 38 years ago. No confidence. That is a big reason why I didn't go on and do my RN nursing. That feeling has stayed with me all these years later.

Embarking on study now was terrifying for me. I would have self-talk of not being good enough...stressing about the work that I handed up. That has changed since doing this course...knowing that I can give some self-love and compassion to me, I am able to complete the studies and do well. All these feelings are normal. It's knowing how to manage these feelings that has made a big difference in the way I approach my studies.

Three months later, a check-in email, delivered the following response:

... I am listening to my meditations nearly every night. I can feel myself relaxing, with each deep breath and my body totally relaxed. Still working on the chatter in my mind. Allowing myself to feel my pain when the tears are flowing, being kind to myself, instead of beating myself up, has really helped me. Being more aware of other people and how they may be struggling, how grateful I am with my life... 


\section{Emily \\ Mother of two (one adult) \\ Working and studying}

Emily was recommended by her counsellor back in 2012, to return to studies to complete a Certificate II in Women's Education. Initially she had a number of negative emotions during her study. She kept asking herself, "Am I wasting my time?"; she didn't understand the relevance of doing a foundation course like Women's Education and wanted to go straight into a veterinary nurse course. Emily never thought about quitting because she believes she always needs to finish what she starts and said that she was a perfectionist. She went on to complete Certificate II, III and then moved onto Cert IV in Mental Health. She struggled with the courses but mainly because at the same time she was studying, her friend was dying and a beloved horse died.

What made her continue foundational studies was the relationships she made with the other students and lecturer. Emily enjoyed being in their company; feeling helpful and appreciated. She said, "I feel good about myself." Emily felt the students' and lecturer's compassion and personally enjoyed being compassionate. She said that she enjoyed making a difference.

At the beginning of 2017, she started university to complete a Bachelor of Social Work on an external capacity because it would increase her chances for employment, better pay and hopefully permanency. She completed one unit but hated every moment of it. She stated that she felt frustrated with operating the on-line university program "Learnline", had difficulty getting the help she needed when she needed it from the lecturer, had constant computer issues, no time to do the things she enjoyed, no time for family, and felt ongoing stress. She received high distinctions, and distinctions for most of her assignments but felt no joy from the results. It was her persistence and her value in finishing something she started coupled with not wanting to waste her money that motivated her to complete the unit. Emily also said that she "doesn't like letting anyone down."

She felt a very strong sense of relief when she decided to defer her university studies, and felt like she could do what she wanted and stated that she "doesn't want to go back" and needed her "life to settle down and have some sense of stability and calmness" before considering a return to education. She participated in the MSC program after she finished the university unit and has since deferred her degree.

During the time, she was undertaking her degree and the MSC course, she experienced:

- Marital disharmony

- Marriage breakup

- Partner having a new relationship

- Moving house

- Selling house

- Settlement issues

- Child not attending school

- Another child facing homelessness and drug abuse.

- Car problems and needed a new car

- Applying for jobs and being unsuccessful

- Under-employment

- Searching to buy a new house 
On a positive note, Emily found her involvement in the MSC program helpful in the sense that it was a reminder to practice mindful self-compassion exercises each week. It kept her focused and she noticed that she needed the encouragement. What it also gave her was awareness of her current situation, "feeling directionless", "feeling of helplessness", her avoidance in doing the exercises, and she stated that she felt "moments of respite, of enjoying a moment of rest, or the beauty of an object, the feel or the smell of something...the mindful part of the practice." She also felt the difference it contributed to her life, because she started acknowledging that she has very "unhelpful self-talk and is trying not to believe it."

However, one of the greatest challenges for her was her struggle with self-compassion. She stated:

I expected to be able to do it with ease, as mindfulness is not new to me. I have found and still do find self-compassion very difficult and uncomfortable... f feel angry when I try to be compassionate with myself and find the cycle of self-hate to stop...I notice the negative fights back twice as hard and self-hate often wins.

I have been surprised at how difficult I am finding this and therefore I feel shame and sadness.

I think all of this is driven by fear of not being able to achieve it (self-compassion) ...

When reflecting on MSC's effect on relationships with other people, she stated:

With some people, it has brought me closer. With others, I feel more able to disengage with their distress.

Her involvement in the MSC course has also given her the insight that if she is going to work successfully in mental health, she needs to master self-compassion.

During the interview, Emily seemed to enjoy the opportunity to reflect on the involvement in the course. She initially was hesitant to "speak her truth", because the research agenda appeared to provide heightened visibility to her situation. However, after talking about her experiences she came to a realisation that she was resisting self-compassion because she was worried about getting in touch with her pain. She felt like a failure during the course, that she was being negative, and not getting out of it what the others "seemed to be getting from it".

The first author also noticed her resistance during the course through the following behaviours:

- Forgetting to bring a pen and paper some weeks

- Coming late

- Not doing the practices at home

- Not accessing emails (had many excuses: computer issues at home, no time...)

- Only completed half of the questionnaire

- She was sick one week but I offered to bring her up to date but she did not take up the offer

- Negative

- Struggling

- Comparing

- Focusing on the past

- Not being mindful at all "not being present" and very judgmental of herself.

At the end of the interview, after having the ability to talk through her experiences, Emily realised that she did not fail the course. In fact, she had become more self-aware of her thoughts and her resistance to self-compassion. She understood that she resists compassion and the "only 
way to get out of it is to go through it." She said that she seemed more "hopeful" and that talking through it was beneficial. She will continue with the practice but Emily said that she needs to be alone. Emily said that she already uses grounding techniques when experiencing extreme stress, and she will also continue with her gratitude practice but include the "why component"; not only explore what she is grateful for but also explore the "why" to further extend benefits derived from the gratitude practice.

Three months post the MSC program, Emily said that she still did not want to go back to university. She explained that she did not like: learning on-line; completing subjects that were more theory-based rather than practically orientated; the academic pressure; and financial strain of book costs. She is considering going back to study at TAFE next year but needs to consider her financial and work situation before committing. She was grateful for the MSC course "shedding the light onto her strengths and issues that need to be worked through" but was still struggling with self-compassion. She is aware that she will need to persist with it and that the struggle will lessen.

\section{Tessa}

Living at home

No dependents

Working

Tessa was the only school leaver in the participant group of four and was mid-way through her Bachelor of Midwifery. She lived at her parents' home and worked on a casual basis whenever she could. Tessa spent long hours with university placements and needed to be available $24 / 7$ for births.

She said that university was a big change from school. The main difficulties were due to a lack of guidance with assignments and essay writing. She also failed a few assignments initially and felt like she "wasn't good enough, a failure, an idiot and that she had no idea what she was doing." This made her feel disappointed, hopeless, insecure and stressed. At times, she thought about missing class because it was pointless and she was not going to understand anything or learn anything new. She reacted by resisting, procrastinating, and generally, being unproductive. Not only did she experience these thoughts and feelings, she found that it manifested in her physical health by decreasing body weight, an increase in acne, and constant tiredness.

When reflecting on the benefits of participating in MSC, she stated:

The most useful thing about this course for me has been learning about the relationship between 'suffering = pain $x$ resistance'...

I also have realised that I was never really mindful and that it can really help me within my daily life as the majority of the time I am thinking about what's next.

The MSC enhanced her wellbeing through:

- Increased mindfulness

- Heightened awareness of stress

- Greater awareness of self-compassion

- Understanding the transferability of mindfulness skills to everyday life as well as academia

- Increased empathy

- Being kind to herself

- Becoming less judgemental 
- Giving her the confidence to ask for help when needed

- Increased motivation to complete university tasks

- Less procrastination

- Greater levels of motivation.

Tessa talked about how she dealt with situations differently due to the MSC training. For example, when dealing with a rude and reactive senior Midwife, she "didn't personalise" and realised that it was the Midwife's issues.

She stated that "I think I am definitely more compassionate to myself when I am struggling with something". She remembered being taught to treat her incessant thoughts by handling them as she would a "small child or cute puppy...gentle and lovingly".

When considering MSC programs benefits, if any, in being used more broadly in $\mathrm{HE}$, she responded:

It can teach students to understand their feelings and that they are not the only ones struggling. I think it is also important that others learn about self-compassion, as uni is stressful and people can be extremely hard on themselves. The concept of common humanity is important for them to understand and to seek help when necessary.

Three months after Tessa had completed her MSC course, Suzie checked via email to see how she was going:

I am still being very self-compassionate and allowing myself time each day to do something other than work. And definitely not resisting as much anymore which is awesome and this ends up giving me more time and makes me more motivated as I'm achieving more things in my days, weeks.

\section{Discussion and Conclusion}

Through the process of gathering data from four adult learners it was discovered that fear, selfdoubt, disillusionment and stress framed their learning journey prior to completing a condensed Mindful Self-compassion course. The feelings and associated action tendencies when approaching studies arose from a myriad of factors internal and external to the participants. For example, internal factors included a lack of confidence and negative self-talk; external factors included a lack of teaching staff, complex online learning platforms, financial strain, with a need to work in paid-employment either part-time or full-time. The participants' descriptions of their learning experience are consistent with evidence in the area [5-13].

Working has become the norm for students studying in tertiary sectors. According to research, $40 \%$ of Australian students have frequent or constant financial stress [4], and $82 \%$ report high psychological distress [9]. Polidano and Zakirova [59] in a study on the outcomes of combining work and tertiary study in South Australia, found that up to $63 \%$ of full time Vocational Educational Training (VET) students are undertaking paid employment with half of these students working over sixteen hours a week in low-paid industries. VET sector students have an additional added stress because most of their courses need to be paid up-front. A study completed by Morris [60] confirmed that the up-front fees "caused significant strain for many respondents, with over $85 \%$ reporting they would like the option to defer fees by means of a student loan." In addition, research on the experiences of hospitality students at a South Australian TAFE (TAFE SA) campus showed that three quarters of respondents felt that work interfered with their study, and nine out 
of ten students felt rushed or pressed for time. Women more frequently reported some level of time pressures (98.1\%) than men (86.5\%)"[60]. The majority of adult learners balance the dual responsibilities of "trying to achieve academically and survive financially" [61].

The pressures and stresses communicated by participants matched those found in the research, however, the Mindful Self-compassion (MSC) course was transformative. For the participants in this study MSC substantially enhanced their wellbeing and for three of the four participants the skills they learnt during the course enabled them to approach higher learning with a greater level of equanimity. When interviewed they shared that they now procrastinated less, had improved focus and confidence, and were developing the ability to stay calm under pressure. The MSC course acted as a springboard to a heightened level of awareness and gave the participants the tools and space to face their fears and express their emotions in relation to their studies and more broadly their personal and professional life. The course helped the adult learners move from negative thought-spirals to positively re-framing situations. They developed increased selfcompassion and gratitude and became less-judgemental of themselves and others and developed better relationships. This evidence is supported by the one other quantitative study which examined how the MSC program affects university students [16].

However, one of the participants, Emily, struggled with the self-compassion component of MSC. To be with the sensation was fine but she did not want to descend into the pain. As noted by Gilbert and Choden [30]:

Compassion is not about ascent and moving above suffering; rather it is about the descent into the grittiness of suffering. We seek to develop compassion not to get rid of our anger, anxiety or pleasurable desires in the first instance, but to hold them in a compassionate space and to develop the wisdom to know how to work with them.

This particular participant was the only one with a background in mindfulness and had already experienced the "honeymoon period" of instant outcomes from doing the practices. Germer [26] called this the first stage of self-compassion practice "infatuation". However, Emily seemed to get stuck in the second phase "disillusionment", where the practice, for some individuals, is hypothesised by Germer to not work anymore. Following Germer's theory, the participants needed to move onto the third stage "true acceptance" of "what is" and the process of "letting go". Emily felt that she understood mindfulness, because she practiced being with the moment but upon reflection (after our discussion), the element she had difficulty with was the nonjudgement component of mindfulness. She was judging herself, comparing her outcome with the other participants, worried about what others thought and struggled with the exercises that focused on being compassionate to herself. Having the opportunity to see her insights written down and discuss her journey at the semi-structured interview after the program, provided her with a platform to reveal this thought process. Emily began to understand that she was not a failure but peaking in terms of self-awareness and needed to work with her personal judgements. With this knowledge, she was able to connect with her core values. In the three months follow up, she noted that she was able to understand what skills she wanted to gain in formal education, and this was to apply theory to practice, rather than solely learn about theoretical constructs. She did not want to perfect essay writing but wanted to strengthen her skill set. Emily discovered that she preferred face-to-face learning, rather than on-line learning; and VET study over HE. She said that when her life stabilises, she may return to education but in the VET sector rather than university. 
In summary, the current research, for the first time, provided a phenomenological context that captured the lived experience of adults learners cultivating mindfulness and self-compassion. The results support previous research in the area, which shows that the characteristic of selfcompassion is an important source of resilience and wellbeing and is a skill and disposition that can be learned [14, 24, 34-39]. Furthermore, the study provided an in-depth narrative description of how individuals develop self-compassion and showed that by learning this skill or disposition, a person is able to: improve their quality of life as a student; positively influence their circle of friends and family; and further, he or she is readily able to apply the skills learned to other areas of their life.

\subsection{The Study's Strengths and Limitations}

The aim of the current research was to capture a holistic account of the students' experiences in relation to their: educational struggles; the effect of learning and practising principles of Mindful Self-Compassion and understanding whether MSC can be used as a tool for ameliorating suffering, enhancing wellbeing and improving the retention of adult learners. Heuristic Inquiry is a method which encourages a deep level of introspection by both the researcher and the participants (co-researchers). It is a qualitative methodology, which like others, such as Interpretative Phenomenological Analysis, is congruent with and complements the practical application of mindfulness [19] and self-compassion. Moustakas [50] summarises that from the beginning and throughout, the process of Heuristic Inquiry involves: "self-search, self-dialogue, and self-discovery; the research question and the methodology flow out of inner awareness, meaning, and inspiration."

Through the process of applying the methodology the first author learned that qualitative depth could not be obtained from every participant. Not everyone is aware of their inner experiences and can articulate them in a comprehensive and life altering manner. Often being involved in anything to do with mindfulness and especially self-compassion, is a new journey ... the individual is travelling on different terrain. This kind of deep inner exploration takes time - longer than six weeks. It may be something best done with willing participants who can dedicate themselves emotionally over a three to six-month period; rather than a research project with a limited time-frame.

Another limitation which the first author noted, was that the participants' reflections - the data gathered - may have been a function of or in part influenced by participants thinking that they needed to please the researcher. This is perhaps a limitation of a number of methodologies and methods when relying on subjective participants' accounts [62]. Research has shown that people being studied may be inclined to report mostly what is to their own advantage or what they think the researcher would like to hear [63].

The first author, through participant Emily's journey, discovered the need of some participants to talk about their experience. We all learn differently and some people need to vocalise their experiences in order to comprehend their learnings. Whilst the first author did welcome and encourage the participants to email her at any time if required, on reflection, she thought that maybe she needed to connect with them more on an individual basis. In contrast, as she researched her own practice, she found that she did not need to vocalise her experiences. She felt that she was able to adequately express herself through art, journaling and poetry. In addition, 
she had the knowledge of the Heuristic Inquiry process to journey with - leading to the question whether it would also benefit participants (co-researchers) to understand and apply this methodological process - something that could be explored in future research.

Additionally, the authors found, similar to other researchers in the field [16] that the condensed MSC course did not adversely affect the study or results, given that it was tailored to pragmatically fit in within the learning demands of the participants. In addition, the qualitative follow up data from the participants indicated long-term benefits of their participation in the condensed MSC program.

\subsection{Conclusion and Recommendations}

In recent years, stress has become a "buzz word" surrounding modern tertiary institutions. Adult learners are arriving on educational campuses with existing problems, stressing about education loans, wondering whether there will be a career waiting for them on the other side, dealing with financial and family pressures of living; and these stressors are all exacerbated when they start their studies. Research has revealed that not only do the stressors and existing mental health problems have a considerable negative effect on students' health, but the wellbeing of students has a considerable effect on their academic performance [5]. Hence, there has been a growth in interest in the mental health and wellbeing of VET and university students [10]. In addition to their general wellbeing, the changes in the higher education and VET sectors funding has resulted in higher educational fees, reduced rate of means-tested student loans and general increasing financial pressures of life [10]. Therefore, balancing work and study commitments has become the norm for most tertiary students.

The broadening access to Australian universities and other levels of adult education institutions is laudable as an achievement because it provides a more equitable access to both domestic and international students, but this greater access creates responsibilities from all levels of government, and education institutions to foster wellbeing of students. With the VET/HE sector recruiting a broader segment of society, institutions need to adopt ethics of care such as is now occurring in primary and secondary education. For example, the wellness philosophy, principles and models, such as the Wheel of Wellness (see Figure 3) are commonly guiding how education is delivered in compulsory education [64].

It is suggested by the authors that this level of care needs to be carried through to the postcompulsory education sector. As can be seen in the current study, the MSC course helped build the internal resilience of adult learners and enabled them to successfully navigate their studies. However, we need to consider these findings within the context of a whole systems wellness model. The MSC course may have less effect in fields where students are studying disciplines such as architecture or law. Skead and Rogers reported that over 35\% of Australian law students experience high to very high levels of psychological distress, even though they often start their studies with equal if not better levels of wellbeing than their peers [12]. Similarly, one of the authors has noticed that in their undergraduate wellness course the topic often has limited effect when excessive levels of demand are placed on students completing Honours or architecture. One of her architecture students reported in his journal:

When the older students greeted us by saying "Welcome to Hell" I brushed it off as a joke but boy were they right. Things got much worse. Picture this: You get to class eager and 
excited, proud of the work that you have created. Instead of praise and congratulations you are met with questions and criticism, the tutor constantly picking apart your work and tearing it down. It can be embarrassing and discouraging. You want to cry but you remember you are standing in front of the entire class. So, the rest of your time at architecture school involves caffeine fuelled sleepless nights and stress in order to avoid a bad critique, to prove yourself instead of to get torn down. It's exhausting, you confess to your tutor that you are tired and they suggest Redbull. It gets so bad you seek out a counsellor and he tells you, "You just need to plan your time better". He doesn't understand although you try to explain, you don't have time. You don't see any friends outside of architecture. You had to quit your job. You don't even eat home cooked meals anymore because it takes too long to prepare. A part of you really wants to give up. You finally get praise and recognition and you're content but then you step back and realise you're a mess and so is everyone around you.

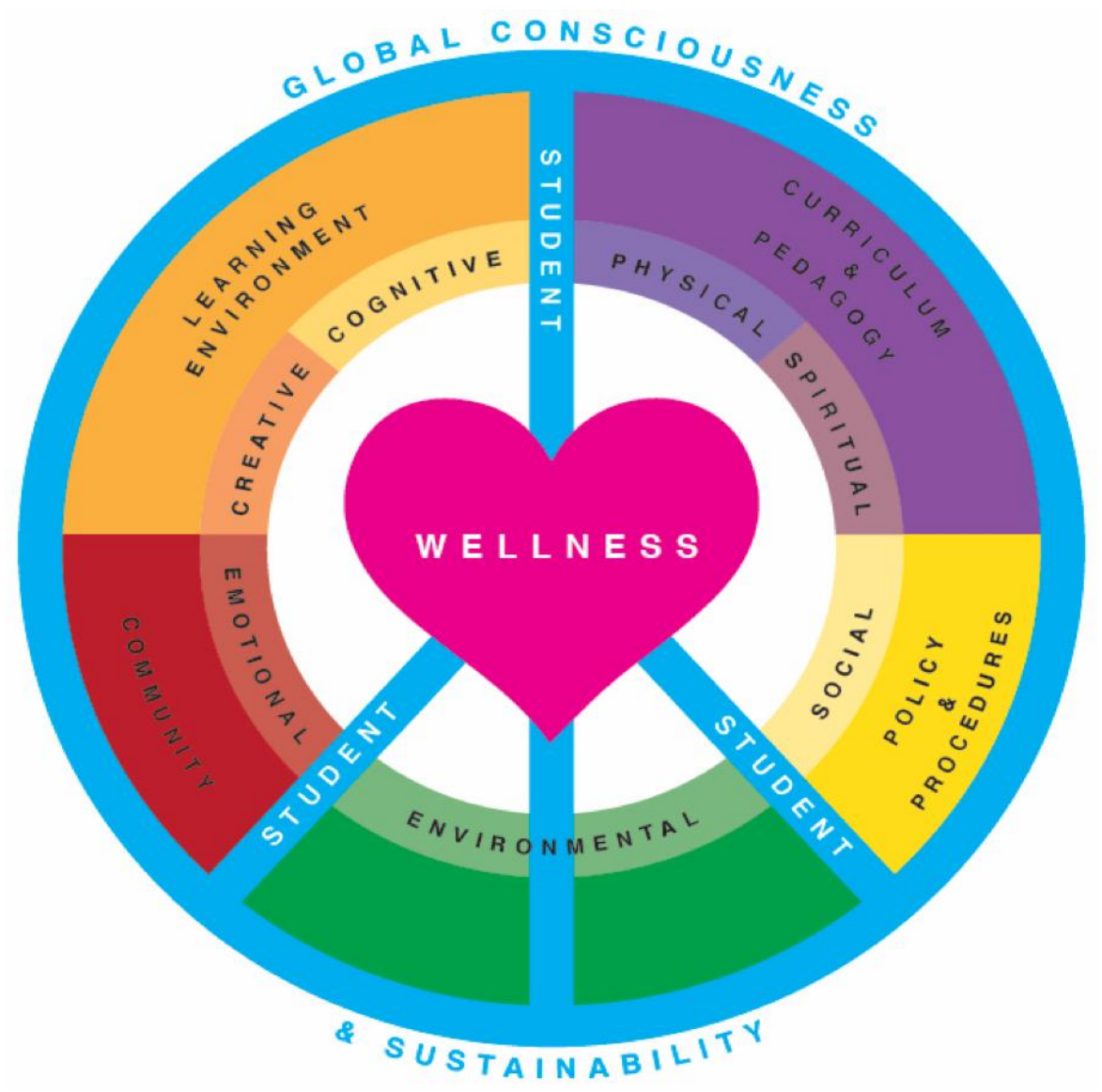

Figure 3 Student wheel of wellness.

Our hope is that this research evokes further discussion, research and financial commitment in supporting adult learners to remain and succeed in education. We need to consider the whole of a learner's wellbeing; examining how various policies and practices are affecting students and make resource building courses like MSC available to adult learners from the onset of their education journeys. This may prevent attrition and help retention. In addition, we hope that all undergraduate teaching qualifications have a core unit exploring mindfulness and self-compassion. The teachers may then become skilled practitioners of the practices - enabling them to implement daily exercises in their classrooms, from pre-school through to the completion of secondary school. 
Our students will then have the potential to benefit on a holistic level; where they are taught not only to educate their minds but also to educate their hearts.

\section{Acknowledgments}

Thank you to Dr Patricia Maria Albrecht for proofreading the article.

\section{Author Contributions}

The first author was the primary researcher of this project and originally documented the results in a Master's thesis.

The second author organised the journal article based on the first author's Master's thesis, added her own material in various sections, synthesized sections and re-wrote a number of parts. New ideas and evidence were added to the work based on the second author's teaching and research experience.

The third author has overseen the development of the research project, publication of the results and forging compassionate professional networks that support academic career pathways for adult learners.

\section{Competing Interests}

The authors have declared that no competing interests exist.

\section{References}

1. Parr N. Who goes to university? The changing profile of our students [internet]. Australia: The Conversation; 2015. Available from: https://theconversation.com/who-goes-to-universitythe-changing-profile-of-our-students-40373.

2. ABoS. 6227.0 - education and work, Australia, May 2017 [Internet]. Canberra: Australian Bureau of Statistics; 2017. [Available from: http://www.abs.gov.au/ausstats/abs@.nsf/mf/62 27.0\%.

3. Australian Goverment DoEaT. 2016 student summary. Australia: Australian Goverment, Department of Education and Training; 2017. Available from: https://docs.education.gov.au/ node/45136.

4. Stallman HM. Psychological distress in university students: A comparison with general population data. Aust Psychol. 2010; 45: 249-257.

5. Andrews A, Chong JL. Exploring the wellbeing of students studying at an australian university. J Aust NZ Student Serv Assoc. 2011; 37: 9-38.

6. Cho J, Yu H. Roles of university support for international students in the united states: Analysis of a systematic model of university identification, university support, and psychological well-being. J Stud Int Ed. 2015; 19: 11-27.

7. El Ansari W, Stock C. Is the health and wellbeing of university students associated with their academic performance? Cross sectional findings from the united kingdom. Int J Env Res Pub Hea. 2010; 7: 509-527.

8. El Ansari W, Stock C. Feeling healthy? A survey of physical and psychological wellbeing of students from seven universities in the uk. Int J Env Res Pub Hea. 2011; 8: 1308-1323. 
9. Mulder AM, Cashin A. Health and wellbeing in students with very high psychological distress from a regional australian university. Adv Mental Health. 2015; 13: 72-83.

10. Robotham D, Julian C. Stress and the higher education student: A critical review of the literature. J Further Higher Ed. 2006; 30: 107-117.

11. Ruus VR, Veisson M, Leino M, Ots L, Pallas L, Sarv ES, et al. Student's well-being, coping, academic success, and school climate. Soc Behav Personality. 2007; 35: 919-936.

12. Skead NK, Rogers S. Stress, anxiety and depression in law students: How student behaviors affect student wellbeing. Monash Univ Law Rev. 2014; 40: 564-587.

13. Toombs M, Gorman D. Recommendations from research into what aboriginal students say affects their social and emotional wellbeing while at university. Aboriginal Islander Health Worker J. 2010; 34: 22.

14. Germer CK, Neff KD. Self-compassion in clinical practice. J Clin Psychol. 2013; 69: 856-867.

15. Bluth K, Blanton PW. Mindfulness and self-compassion: Exploring pathways to adolescent emotional well-being. J Child Fam Stud. 2014; 23: 1298-1309.

16. Smeets $E$, Neff $K$, Alberts $H$, Peters M. Meeting suffering with kindness: Effects of a brief self-compassion intervention for female college students. J Clin Psychol. 2014; 70: 794-807.

17. Reyes D. Self-compassion a concept analysis. J Holist Nurs. 2012; 30: 81-89.

18. Albrecht NJ, Albrecht $\mathrm{P}$, Cohen M. Mindfully teaching in the classroom: A literature review. Aust J Teach Ed. 2012; 37: 1-14.

19. Albrecht NJ. Teachers teaching mindfulness with children: An interpretative phenomenological analysis. Unpublished doctoral dissertation, School of Education, Flinders University of South Australia www researchgate net/publication/311376289. 2016.

20. Albrecht NJ. Teachers teaching mindfulness with children: Being a mindful role model. Aust J Teach Ed. 2018; 43: 23.

21. Purser RE, Milillo J. Mindfulness revisited: A buddhist-based conceptualization. J Manage Inq. 2015; 24: 3-24.

22. Neff K, Germer C. The mindful self-compassion workbook: A proven way to accept yourself, find inner strength, and thrive. New York: Guilford Press; 2018.

23. Stahl B, Goldstein E. A mindfulness-based stress reduction workbook. Oakland: New Harbinger Publications; 2010.

24. Kyeong LW. Self-compassion as a moderator of the relationship between academic burn-out and psychological health in korean cyber university students. Personality Individual Differ. 2013; 54: 899-902.

25. Burnell L. Compassionate care: A concept analysis. Home Health Care Manage Pract. 2009; 21: 319-324.

26. Germer CK. The mindful path to self-compassion: Freeing yourself from destructive thoughts and emotions. New York: The Guilford Press; 2009.

27. Neff K. Self compassion: Stop beating yourself up and leave insecurity behind. New York: HarperCollins Publishers; 2011.

28. Neff K, Germer CK. A pilot study and randomized controlled trial of the mindful self-compassion program. J Clin Psychol. 2013; 69: 28-44.

29. Neff KD, Dahm KA. Mindfulness and Self-Regulation. New York: Springer; 2015. p. 121-137.

30. Gilbert $P$, Choden. Mindful compassion: Using the power of mindfulness and compassion to transform our lives. Great Britain: Constable and Robinson Ltd; 2013. 
31. Goetz JL, Keltner D, Simon-Thomas E. Compassion: An evolutionary analysis and empirical review. Psychol Bull. 2010; 136: 351-374.

32. Neff KD. Self-compassion: An alternative conceptualization of a healthy attitude toward oneself. Self Identity. 2003; 2: 85-101.

33. Neff KD. The development and validation of a scale to measure self-compassion. Self Identity. 2003; 2: 223-250.

34. Neff K, Hsieh Y, Dejitterat K. Self-compassion, achievement goals, and coping with academic failure. Self Identity. 2005; 4: 263-287.

35. Neely ME, Schallert DL, Mohammed SS, Roberts RM, Chen YJ. Self-kindness when facing stress: The role of self-compassion, goal regulation, and support in college students' wellbeing. Motivation Emot. 2009; 33: 88-97.

36. Williams JG, Stark SK, Foster EE. Start today or the very last day? The relationships among self-compassion, motivation, and procrastination. Am J Psychol Res. 2008; 4: 37-44.

37. Iskender $\mathrm{M}$. The relationship between self-compassion, self-efficacy, and control belief about learning in turkish university students. Soc Behav Personality. 2009; 37: 711-720.

38. Wei M, Liao KYH, Ku TY, Shaffer PA. Attachment, self-compassion, empathy, and subjective well-being among college students and community adults. J Personality. 2011; 79: 191-221.

39. Leary MR, Tate EB, Adams CE, Batts Allen A, Hancock J. Self-compassion and reactions to unpleasant self-relevant events: The implications of treating oneself kindly. J Personality Soc Psychol. 2007; 92: 887.

40. Olson K, Kemper KJ, Mahan JD. What factors promote resilience and protect against burnout in first-year pediatric and medicine-pediatric residents?. J Evid-Based Compl Alt. 2015; 20: 192-198.

41. Şenyuva E, Kaya H, Işik B, Bodur G. Relationship between self-compassion and emotional intelligence in nursing students. Int J Nurs Pract. 2014; 20: 588-596.

42. Frick WB. The symbolic growth experience. J Humanistic Psychol. 1983; 23: 108-125.

43. Frick WB. The symbolic growth experience: A chronicle of heuristic inquiry and a quest for synthesis. J Humanistic Psychol. 1990; 30: 64-80.

44. Colver MC, El-Alayli A. Getting aesthetic chills from music: The connection between openness to experience and frisson. Psychol Music. 2016; 44: 413-427.

45. Maslow AH. Religions, values, and peak-experiences. Columbus: Ohio State University Press C; 1964.

46. Csikszentmihalyi M. Flow: The psychology of happiness. London: Rider; 1996.

47. Denford-Wood G. Mindfulness and education: Research and practice. Newcastle upon Tyne: Cambridge Scholars Publishing; 2017. p. 125-149.

48. Denford-Wood G. Enhancing teacher wellbeing sociopoetically through the mindfulness of seminaria. Int J Sch Clim Violence Prev. 2017; 2: 62-89.

49. Moustakas C. Loneliness. Englewoods Cliffs: Prentice-Hall; 1961.

50. Moustakas C. Heuristic research: Design, methodology, and applications. London: Sage Publications; 1990.

51. Anderson R. Intuitive inquiry: Interpreting objective and subjective data. ReVision. 2000; 22: 31-31.

52. Djuraskovic I, Arthur N. Heuristic inquiry: A personal journey of acculturation and identity reconstruction. Qual Rep. 2010; 15: 1569. 
53. Moustakas C. Phenomenological research methods. Thousand Oaks: SAGE Publications Ltd; 1994.

54. Smith J, Flowers $P$, Larkin M. Interpretative phenomenological analysis. Theory, practice and research. London: SAGE Publications Limited; 2009.

55. Neff KG, CD. The mindfulness self-compassion workbook. 2016.

56. Elliott R, Fischer CT, Rennie DL. Evolving guidelines for publication of qualitative research studies in psychology and related fields. Brit J Clin Psychol. 1999; 38: 215-229.

57. Tracy SJ. Qualitative quality: Eight "big-tent" criteria for excellent qualitative research. Qual Inq. 2010; 16: 837-851.

58. Flick U. An introduction to qualitative research. London: Sage Publications; 2014.

59. Polidano C, Zakirova R. Outcomes from combining work and tertiary study. A national vocational education and training research and evaluation program report. Adelaide: National Centre for Vocational Education Research; 2011.

60. Morris M. 'Trying to keep up': The experience of combining full-time vet with work. Aust J Adult Learn. 2013; 53: 44.

61. Carney C, McNeish S, McColl J. The impact of part time employment on students' health and academic performance: A scottish perspective. J Further Higher Ed. 2005; 29: 307-319.

62. Albrecht NJ. Connection of a different kind: Teachers teaching mindfulness with children. Waikato J Ed. 2016; 21.

63. Cropley AJ. Creativity in education \& learning: A guide for teachers and educators. Long Range Planning. 2002; 35: 199-200.

64. Albrecht N. Wellness: A conceptual framework for school-based mindfulness programs. Int J Heal Wellness Soc. 2014; 4.

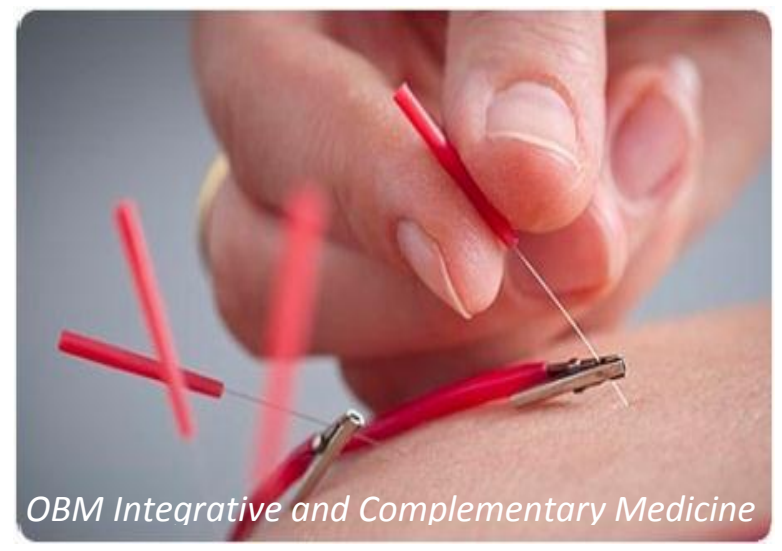

Enjoy OBM Integrative and Complementary Medicine by:

1. Submitting a manuscript

2. Joining in volunteer reviewer bank

3. Joining Editorial Board

4. Guest editing a special issue

For more details, please visit: http://www.lidsen.com/journals/icm 